\title{
List of Illustrations
}

1. Photo of Lev Semionovich Vygotsky ............................................................... 19

2. Photos of Basil Bernstein:
a. Basil Bernstein at a congress
130
b. Basil Bernstein in the Royal Air Force ....................................................... 139

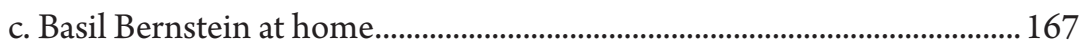


